gonadotrophin in Melbourne between 1976 and 1978 . Creutzfeldt-Jakob disease was the cause of death in a woman aged 39 also living in Adelaide who had received human pituitary gonadotrophin in 1979. She had been treated with the same batch of human pituitary gonadotrophin as the index case. Twenty eight other Australian women are known to have been treated with that batch. A fourth woman died from Creutzfeldt-Jakob disease in Western Australia in 1991 after receiving human pituitary gonadotrophin.

The human pituitary hormone programme started in Australia in 1964. By 1985 the programme had supplied human growth hormone for 664 children with short stature and pituitary gonadotrophin for 1447 adults with infertility. ${ }^{8}$ From its inception the Australian programme used a column chromatographic purification procedure to extract the hormones. Up to 800 cadaver pituitary glands were pooled to provide a single batch. Australia was one of the few countries in which gonadotrophins derived from pituitary glands were used to treat infertility. Most countries preferred to use gonadotrophins derived from urine from postmenopausal women. More recently both gonadotrophins and growth hormone have been derived with recombinant technologies. In Britain a few women were treated with pituitary gonadotrophin at the Birmingham and Midland Hospital for Women in the 1960s, but urinary gonadotrophins were substituted in the early 1970s. Any women who acquired Creutzfeldt-Jakob disease from this source are likely already to have died. ${ }^{9}$

The chief medical adviser to the Australian Commonwealth Department of Health recommended in 1990 that patients who had received pituitary hormones should be advised by their medical practitioners never to donate blood, corneas, or other tissues. Although it was believed that vertical transmission from a pregnant woman to her baby could not occur, Japanese workers have already found infectious material in placental and umbilical cord blood. ${ }^{10}$ The Australian government has funded a special counselling service in addition to that provided by individual consultants and clinics for patients who received pituitary hormones.

Further research is needed into the natural mechanism of spread of the agent causing Creutzfeldt-Jakob disease. The Australian Attorney General's Department is examining the issue of compensation for the families concerned in these tragedies. A prospective case registry is being established to enable continued epidemiological surveillance of all Australian patients who received pituitary hormones. This is no easy task, but it is hoped that these mechanisms will provide patients and their families with accurate information on this public health issue.

DAVID L HEALY Professor

Monash University Department of

Obstetrics and Gynaecology,

Monash Medical Centre,

Clayton 3168,

Victoria, Australia

Department of Obstetrics and Gynaecology,

University of Melbourne,

Royal Women's Hospital,

Carlton 3053,

Victoria, Australia

1 Lazarus L. Suspension of the Australian human pituitary hormone programme. Med $\mathcal{f}$ Aust 1985;143:57-9.

2 Hintz R. Untoward events in patients treated with growth hormone in the USA. Horm Res 1992;38:44-9.

3 Rappaport EB. Iatrogenic Creutzeldt-Jakob disease. Neurology 1987;37:1520-2.

4 Weissmann C. A unified theory of prion propagation. Nature 1991;352:679-83.

5 Prusiner SB. The molecular biology of prion diseases. Science 1991;252:1515-22.

6 Collinge J, Palmer MS, Dryden AJ. Genetic predisposition to iatrogenic Creutzfeldt-Jakob disease. Lancet 1991;337:1441-2.

7 Cochius II, Burns RJ, Blumbergs PC, Mack CK, Alderman CP. Creutzfeldt-Jakob disease in a recipient of human pituitary derived gonadotrophin. Aust NZ $\mathcal{F}$ Med 1990;20:592-4.

8 Lazarus L. Creutzfeldt-Jakob disease and human pituitary-derived hormone therapy. Royal Australian College of Physicians: Fellowship Affairs. November 1991:21-8.

Australian College of Physicians: Fellowship Affairs. November 1991:21-8.
Pfeffer N. Early infertility treatments derived from human pituitary. BMF 1993;306:1128-9.

9 Pfeffer N. Early infertility treatments derived from human pituitary. BM 7 1993;306:1128-9. transmissible agent in tissue from a pregnant woman with Creutzfeldt-Jakob disease. N Engl $\mathcal{F}$ Med 1992;327:649.

\title{
The role of doctors in promoting smoking cessation
}

\author{
Doctors can't do much on their own; public policy can
}

In 1979 Russell and his colleagues published what would become one of the most cited and inspirational papers in the history of research into stopping smoking. ${ }^{1}$ They found that doctors who gave their patients brief advice and "warned" that they would follow them up could expect a $5 \cdot 1 \%$ increase in the number who stopped smoking for at least 12 months beyond that in controls who received no advice. Their most resonant observation was the extrapolation that if all British general practitioners were routinely to follow this simple advisory regimen an annual yield of some 500000 ex-smokers could result.

Their work has since inspired dozens of replications in different primary care settings (general practices, dental practices, outpatient clinics, hospitals, and antenatal groups and with patients who have had coronary events or other smoking related diseases). The most rigorously evaluated of these are the subject of a new review monograph by Sanders from a project funded by the Health Education Authority. ${ }^{2}$

The monograph joins several other recently published reviews that have reached broadly similar conclusions. ${ }^{3-8}$ These are, firstly, that interventions with motivated volunteers not surprisingly produce better cessation rates than those tried in randomly selected patients. Secondly, if doctors say something about cessation, however brief, to their smoking patients a small, but often significant, number of these will go on to quit compared with those with whom the subject has been avoided.

Thirdly, if something more extensive is done, such as pursuing the issue in line with a protocol over several consultations, setting a date for stopping and following this up with an appointment, or trying to personalise the message to a patient's particular condition or circumstances, better results are generally achieved. This may, however, simply be a consequence of more motivated smokers being willing to attend more time consuming interventions.

Lastly, cessation rates tend to be higher when a nicotine replacement product is prescribed than when the intervention is only advice or counselling. Nevertheless, the generally nonsignificant differences that are found between active and placebo gum tend to suggest that it may be the accoutrements of both counselling about the gum and the way gum constantly reminds smokers that they are trying to quit that produce the effect.

If the original extrapolation by Russell's group ("if all general practitioners were to...") inspired many subsequent clinical trials; unfortunately it did not have the same effect on 
general practitioners at large. The depressing fact remains that nothing remotely like all general practitioners counsel their smoking patients, let alone even realise that many of them smoke. In Australia, for example, where less than $10 \%$ of doctors smoke, general practitioners knowingly under the gaze of a research project examining their preventive interactions with patients could successfully identify only $56 \%$ of their smoking patients. ${ }^{9}$ In countries where much higher proportions of doctors and medical students smoke ${ }^{11}$ sometimes even higher proportions than in the adult population-the picture must surely be bleaker.

General practitioners have more than enough cessation packages and minimal intervention protocols available to them. By comparison, there have been few efforts to analyse why many doctors do not even raise the subject with their patients and why initial enthusiasm to attend training courses in cessation tends to wane when implementation is examined away from clinical trial settings. ${ }^{12} 13$

Few doctors would continue to prescribe a drug that "failed" $95 \%$ of the time-one, unkind, interpretation of the usual long term outcome of cessation protocols with minimal intervention. Doctors' training and their day to day expectations of achievement with drug treatments probably mean that many of them carry analogous expectations into their counselling of patients about smoking and the prescription of nicotine substitutes. There is no realistic hope that such expectations will ever be fulfilled, so for many doctors the result is probably despondency and diminished efforts with such patients.

Efforts should certainly continue to encourage doctors to make the most of the powerful opportunity offered by a clinical setting to encourage their patients to stop smoking. More needs to be done to show doctors that, although their success rate with individual patients may seem small, it is important in public health terms. But, plainly, for as long as the choice to smoke is made easy by the cultural, political, and economic environment so the clinical role of doctors in encouraging cessation will often seem futile.

Doctors have been in the forefront of public health lobbying for regulatory and fiscal "fences at the top of the cliff" that reduce the number of people falling into the rivers of long term tobacco use. Yet there may be a counterpart in smoking cessation to Julian Tudor Hart's “inverse care law."14 A testing of the inverse smoking research law would doubtless reveal that the more capable the intervention or policy of reducing the prevalence of smoking - for example, price rises, ${ }^{15}$ bans on smoking in the workplace, ${ }^{16}$ and advertising restrictions ${ }^{17}$ - the scarcer the research that describes its implementation.

Conversely, research about the minutiae of "downstream" approaches to smoking control oriented to the individual person continue to proliferate, with the generally unexceptional outcomes that Sanders has summarised. I look forward to the day when the Health Education Authority commissions a monograph that points to more effective ways in which doctors and others can undermine the British government's continuing defence of tobacco advertising.

SIMON CHAPMAN

University of Sydney,

Senior lecturer in community medicine

Westmead Hospital,

Westmead 2145,

Australia

1 Russell $M$, Wilson $C$, Taylor $C$, Baker $C$. Effect of general practitioners' advice against smoking. BMF 1979;ii:31-5.

2 Sanders D. Smoking cessation interventions: is patient education effective? London: Health Promotion Services Unit, London School of Hygiene and Tropical Medicine, 1992.

3 Ockene JK. Physician-delivered interventions for smoking cessation: strategies for increasing effectiveness. Prev Med 1987;16:723-37.

4 Schwartz J. Review and evaluation of smoking cessation methods: the US and Canada 1978-1985. Bethesda: National Institutes of Health, 1987

5 Lam W, Szc PC, Sacks HS, Chalmers TC. Meta-analysis of randomised controlled trials of nicotine chewing-gum. Lancet 1987;ii:27-30.

6 Kottke TE, Battista RN, Deffiesc GH, Brekke ML. Attributes of successful smoking cessation interventions in medical practice. A meta-analysis of 39 controlled trials. $7 A M A$ 1988;259: 2883-9.

7 Glynn TJ, Boyd GM, Gruman JC. Essential elements of self-help/minimal intervention strategies for smoking cessation. Health Education Quarterly 1990;17:329-45.

8 Mattick RP, Baillie A, eds. An outline for approaches to smoking cessation: quality assurance project. Canberra: Australian Government Publishing Service, 1992. (National Campaign Against Drug Canberra: Australian Gover

9 Dickinson J, Wiggers J, Leeder S, Sanson-Fisher R. General practitioners' detection of patients' smoking status. Med $\mathcal{F}$ Aust 1989;150:420-6.

10 Tessier JF, Fréour P, Belougne D, Crofton J. Smoking habits, and attitudes of medical students towards smoking and anti-smoking campaigns in fourteen European countries. Eur Epidemiol 1989;5:311-9

11 Tessier JF, Fréour P, Nejiari C, Belougne D, Crofton JW. Smoking behaviour and attitudes towards smoking of medical students in Australia, Japan, USA, Russia, and Estonia. Tobacco Control 1993;2:24-9.

12 Copeman RC, Swannell PJ, Pincus DF, Woodhead KA. Utilization of the "smokescreen" smoking-cessation programme by general practitioners and their patients. Med f Aust 1989;151:83-7.

13 Borland R, Hill D. Are doctors doing enough to stop their patients smoking? Med $f$ Aust 1989;150:413-4.

14 Hart JT. The inverse care law. Lancet 1971;1:405-12.

15 Wasserman J. How effective are excise tax increases in reducing cigarette smoking? Am f Public Health 1992:82:19-20.

16 Woodruff TJ, Rosbrook B, Pierce J, Glantz SA. Lower levels of cigarette consumption found in Woodruff TJ, Rosbrook B, Pierce J, Glantz SA. Lower levels of cigarette
smoke-free workplaces in California. Arch Intern Med 1993;153:1485-93.

17 Laugesen $M$, Meads C. Tobacco advertising restrictions, price, consumption in OECD countries, 1960-1986. Br f Addict 1991;86:1343-54.

\section{Steroid osteoporosis}

\section{A pragmatic approach is needed while prospective trials are awaited}

The adverse effects of corticosteroids on bone have been known for over 50 years. We are now able to document these changes with reasonable accuracy by using bone densitometry, but we still do not know the mechanisms or the safe dose of steroids in a given period. Nor it is known whether steroid osteoporosis is preventable.

Studies of patients receiving long term steroid treatment for chronic diseases such as asthma, rheumatoid arthritis, or inflammatory bowel disease have shown that bone loss seems to be rapid initially with rates approaching 4-10\% a year, ${ }^{23}$ but, while bone loss is greatest in the first year, it probably continues for as long as treatment is being given. This loss of bone is important, but clinically osteoporotic fractures are the relevant end point, and there are few data on the association of steroids with fractures. Increased rates of vertebral fractures have been reported in many studies of patients with chronic diseases, but some of that increase may be attributable to the underlying disease. ${ }^{47}$ Steroids affect cortical sites (such as the neck of femur) as much as trabecular bone in the vertebra, ${ }^{3}$ but whether there is an increased risk of hip fracture in addition to the commonly associated vertebral and rib fractures is unknown. Some studies suggest that patients taking steroids suffer vertebral fractures at higher thresholds of spinal bone density than non-users, ${ }^{8}$ but by no means all patients taking steroids develop fractures. The wide variation may reflect genetic differences in susceptibility to corticosteroids or variability in the pharmacokinetics of steroids among individual people. Furthermore, some steroid bone loss is completely reversible, as shown by the follow up of patients treated for Cushing's syndrome ${ }^{9}$ and examination of 